\title{
Orthopedic Treatment of Clavicle Fracture in Adulthood at Sylvanus Olympio Teaching Hospital of Lome (Togo): Functional and Anatomical Results
}

\author{
Ananivi Sogan, (MD, Surgeon, MSc in Anatomy) \\ Efoe-Ga Amouzou, (MD, Surgeon, specialist registrar) \\ Yaovi Dellanh, (MD, Orthopedic Surgeon, specialist registrar) \\ Komlan Adabra, (MD, Surgeon, Assistant professor) \\ Anani Abalo, (MD, Orthopedic Surgeon, Professor) \\ Assang Dossim, (MD, Orthopedic Surgeon, Professor) \\ University of Lome, Togo
}

Doi: 10.19044/esj.2018.v14n30p63 URL:http://dx.doi.org/10.19044/esj.2018.v14n30p63

\begin{abstract}
Background: Fractures of the clavicle are relatively frequent and are benign lesions. Their management may be nonoperative or surgical. The objectives of this study were to determine the functional and anatomical outcome of fractures of the adult clavicle after nonoperative treatment. Materials and methods: Two years retrospective study was done. It rolled patients with clavicle fracture treated with either plaster bolero, scarf or clavicular brace with or without rehabilitation, who gave informed consent and who agreed to provide us initial and control radiological pictures. The objective results were evaluated by the Constant score and radiological control images. The subjective results were mainly represented by the impressions of the patients. Results: We recorded 171 cases of clavicle fracture in adults, or $6.2 \%$ of fractures in general, including 53 women. The sample studied consisted of 114 cases, including 12 women. In the majority of cases the constant score was either good, $65.8 \%$ or excellent, $20.7 \%$. We have not noticed a poor result. Radiologically, the evolution was marked by $90.4 \%$ of vicious callus and $2.6 \%$ of pseudarthrosis. More than half of the patients, $62.2 \%$ were satisfied with the results of the nonoperative treatment received. Conclusion: The evolution of the fractures of the clavicle after nonoperative treatment was therefore favorable on the functional level but marked by vicious callus and pseudarthrosis.
\end{abstract}

Keywords: Clavicle fracture; adult; nonoperative treatment; Togo 


\section{Introduction}

Subcutaneous position of the clavicle and its S-like shape make it extremely fragile to traumatic agents. Clavicle fractures $(\mathrm{CF})$ in adulthood are therefore common and represent 2.6 to $10 \%$ of fractures in general (Robinson, 1998; Postacchini et al., 2002) and 35 to $44 \%$ of shoulder area fracture (Postacchini et al., 2002). Although the diagnosis of CF is often obvious trough clinical and radiological findings, its management stills have no consensus (Faldini et al., 2010; Cho et al., 2010). Traditional non-operative treatment of $\mathrm{CF}$ remains relevant nowadays and most used in low-income countries. At Sylvanus Olympio Teaching Hospital (SOTH) of Lome in Togo, orthopedic treatment is the most used for patients admitted in emergency for CF. The aim of the study was to present the outcomes of patients orthopedically treated for $\mathrm{CF}$ and especially the functional and anatomical results of this treatment.

\section{Materials and Methods}

Based on the SOTH Clinic records, 171 adult (over 15 years old) who had sustained a confirmed CF (X-ray or CT-Scan exams) from the years 2011 to 2013; who had been treated non-operatively and reviewed in control with a new X-ray or a new CT-Scan were included in this retrospective study. We did not include patients with a history of traumatic or non-traumatic scapular belt disease prior to clavicle fracture in our study. We excluded 57 patients who were unable to respond to the interview (Figure 1). There were 3 patients in the sample whose fracture had been complicated by non-union and were already operated and, therefore, excluded from the Constant's score evaluation. All patients gave informed consent to participate in this study. The outcome measures were functional, anatomic and subjective results.

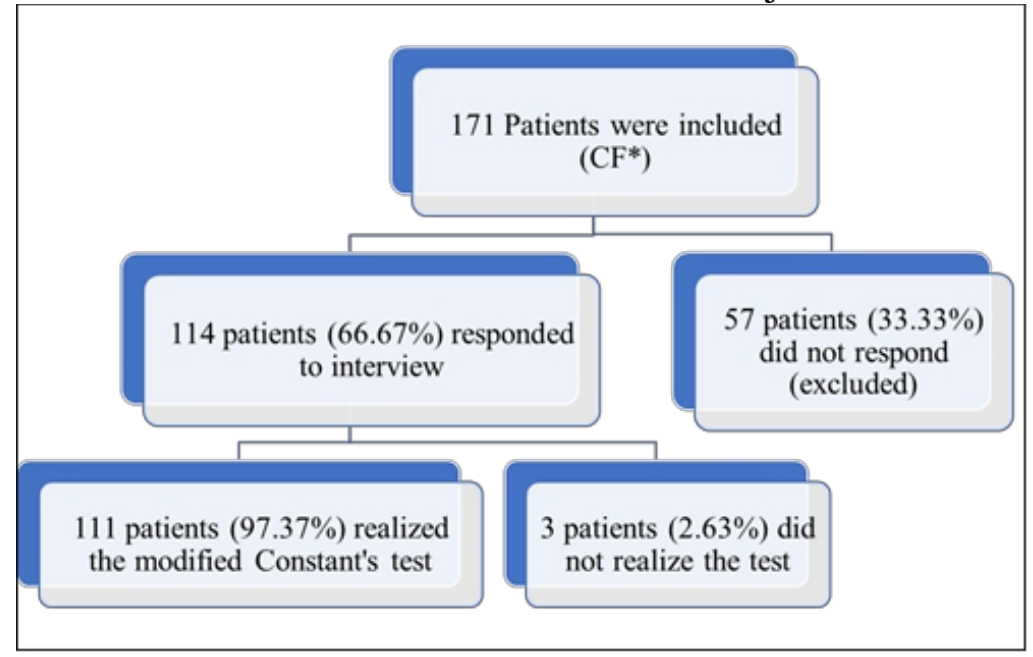

*Clavicle fracture

Figure 1 : Study flow chart 
Functional results consisted in Constant's score (Constant, 1987) that have been modified because of unavailability of objective measuring instruments of the motor force (dynamometer, or microFET2) at STOH. We used masses from 1 to $5 \mathrm{~kg}$ for the estimation of the motor force. Ranging from 50 to 100 , this is a score that is either poor, average, good or excellent. Anatomical evaluation was made from standard radiographs control. The consolidation period chosen was six to eight weeks. The diagnosis of nonunion was made in the absence of consolidation of the clavicle fracture beyond three months. Subjective results have been likened to patients' impressions of the future of the traumatized shoulder after nonoperative treatment. Thus, the patients were either satisfied or not satisfied.

Statistical analysis was done using Epi Info $^{\mathrm{TM}}$ 7.1.5 (CDC, Atlanta, USA) by a statistician. qualitative data was presented as count (percent). Continuous data is presented as mean (range $=\min -\max , \mathrm{SD}=$ standard deviation). Comparisons of qualitative variables between patients were done using the chi-square test. $\mathrm{P}$ value below or equal 0.05 was considered statistically significant.

\section{Results}

CF in adults were found in 171 cases (including 53 women), over 2758 patients admitted in orthopedics, which represent $6.20 \%$ of fractures. The sample in our study consisted of 114 patients including 12 women. The mean age of our patients was 35.07 years (range $=17-70, \mathrm{SD}=10.43$ ). The most represented age group was 25 to 34 years old with a percentage of $38.59 \%$ ( $\mathrm{n}=$ 44) (Figure 2).

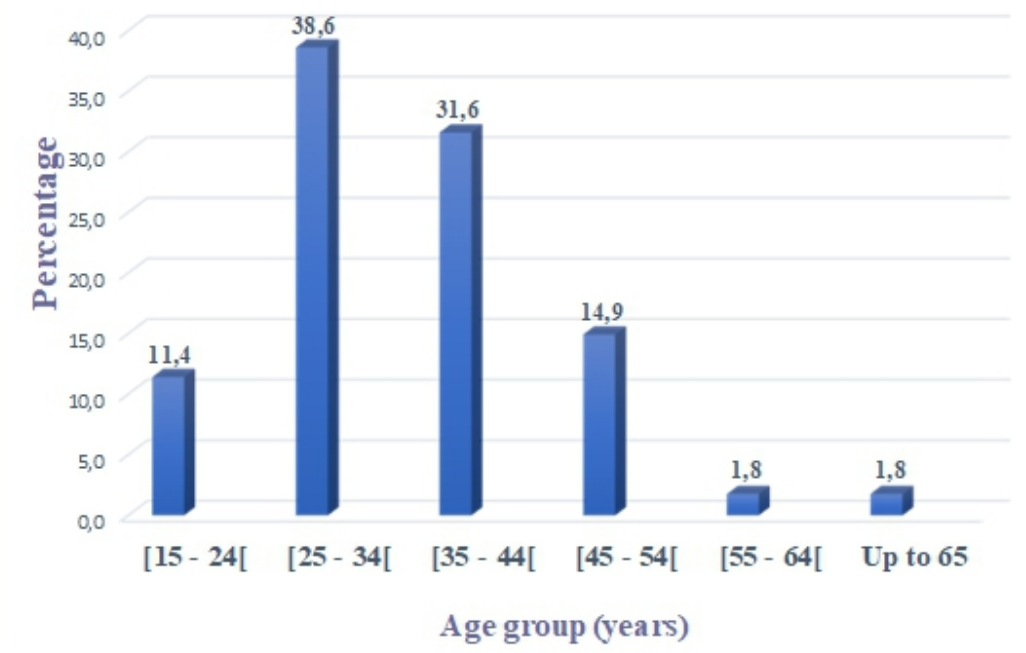

Figure 2 : Age group 


\section{- Injury report and treatment received:}

The left clavicle was the most affected in our study, with $62.28 \%$ of cases $(n=71)$. There was no bilateral involvement. Fractures were localized in $82.45 \%(\mathrm{n}=94)$ in the middle third; the external third in $12.3 \%(\mathrm{n}=14)$ and the internal third $5.26 \%(\mathrm{n}=6)$. There were 101 cases of displaced CF $(88.59 \%)$ in our study. The displacements were essentially the overlap in 58 patients $(57.42 \%)$ and the translation in 37 patients (36.63\%) (Table I). In our sample, $97.36 \%$ of our patients $(n=111)$ benefited from immobilization by plaster bolero. The other patients benefited from immobilization of the traumatized shoulder either by a scarf or by a clavicular brace. The average immobilization time with plaster bolero was 44.43 days (range $=30-90, \mathrm{SD}=$ 11.62).

Table I : Type of displacement

\begin{tabular}{lcc}
\hline & Total patients & Percentage \\
\hline No displacement & 13 & 11.40 \\
Overlap $>2 \mathrm{~cm}$ & 18 & 15.79 \\
Overlap $<2 \mathrm{~cm}$ & 16 & 14.04 \\
Translation & 12 & 10.53 \\
Angulation & 6 & 5.26 \\
Overlap + interfragmentary gaps & 7 & 6.14 \\
Translation + interfragmentary gaps & 8 & 7.02 \\
Overlap +angulation & 17 & 14.91 \\
Translation + angulation & 17 & 14.91 \\
Total & 114 & 100 \\
\hline
\end{tabular}

\section{- Results of non-operative treatment:}

The score was appreciated in 111 patients. The constant score was either good, $65.77 \%(\mathrm{n}=73)$ or excellent, $20.72 \%(\mathrm{n}=23)$. We did not notice a poor result (Table II). We did not find a statistically significant correlation between the constant score and the fracture immobilization type $(\mathrm{p}=0.065)$. Radiographic results were mainly marked by vicious callus but with good rate of consolidation (Table III, Figure 3 and 4). As far as the subjective results are concerned, 69 patients $(62.16 \%)$ were satisfied with the outcome of the orthopedic treatment made. There was a statistically significant correlation between the Constant's score and the subjective results $(p<0,01)$. The higher the Constant's score is, the more satisfied patients are with the treatment received. Concerning Post-therapeutic sequelae, 71 patients (63.96\%) reported no discomfort after treatment; 17 patients $(15.32 \%)$, complained of pain during exercise. 
Table II : Modified Constant's score results

\begin{tabular}{lcc}
\hline & Total patients & Percentage \\
\hline Excellent & 23 & 20.72 \\
Good & 73 & 65.77 \\
Average & 15 & 13.51 \\
Poor & 0 & 0 \\
Total & 111 & 100 \\
\hline \multicolumn{3}{c}{ Table III : Radiological results. } \\
\hline \multicolumn{3}{c}{ Total patients } \\
\hline ad integrum recovery & 8 & Percentage \\
Vicious callus with shortening & 88 & 7.02 \\
Vicious callus without shortening & 15 & 77.19 \\
Nonunion & 3 & 13.16 \\
Total & 114 & 2.63 \\
\hline
\end{tabular}

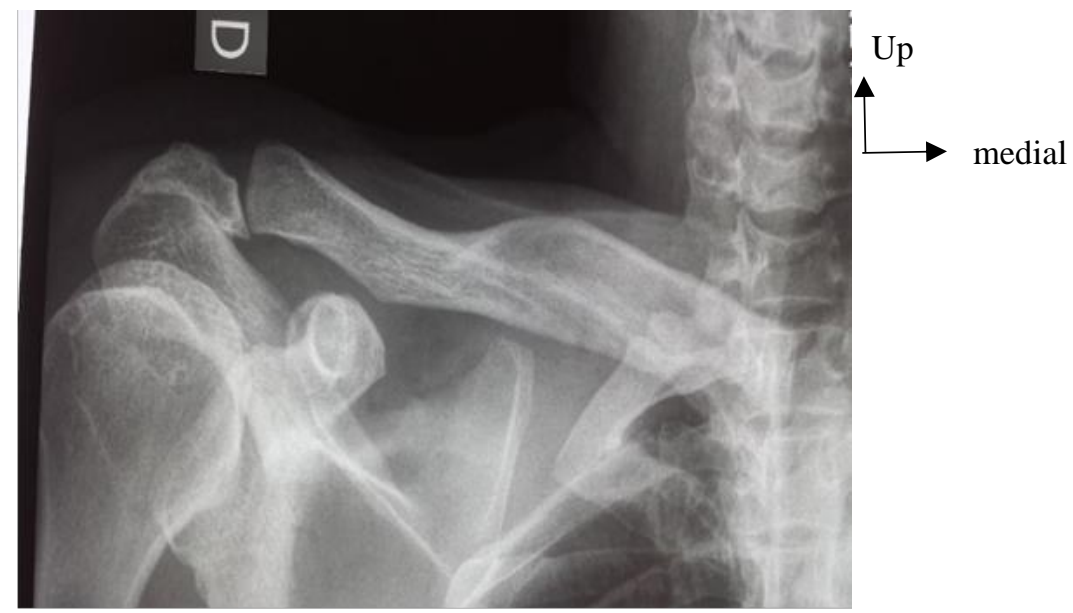

Figure 3 : vicious callus of lateral-end with shortening of right clavicle (Radiograph)

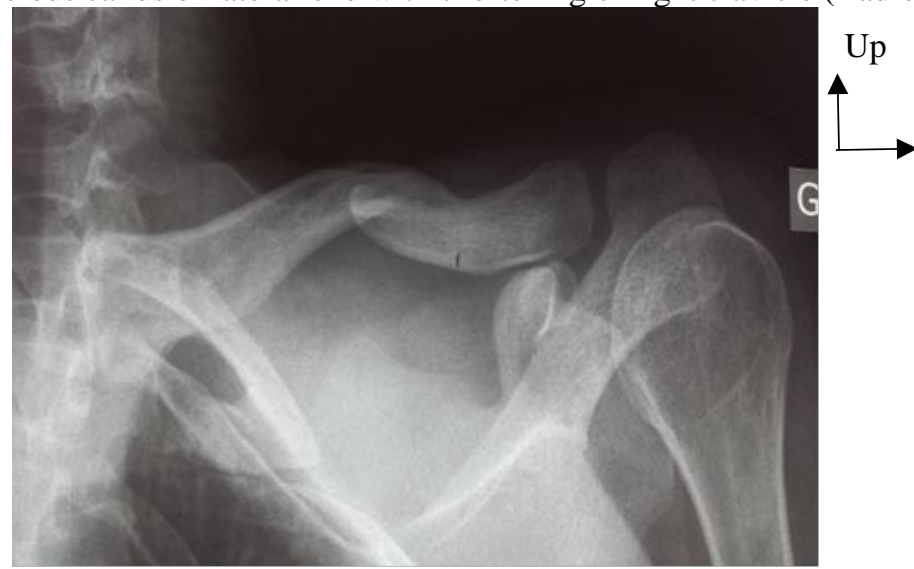

Figure 4 : vicious callus of midle and lateral-end union with shortening of left clavicle (Radiograph) 


\section{Discussion}

We realized a retrospective study that requires patients consent and their presence in order to evaluate the functional results using modified Constant's Score, and anatomical result by using patient standard radiographs control. One of the main limits of our study is the exclusion of 57 cases of CF who did not wanted to come back for the functional and anatomical evaluations. Another limit of this study is the retrospective design. It could be better if it was a prospective study which could help us having a better follow up of patients; and those one would have given in advance informed consent.

The plaster bolero was the most used therapeutic method of contention in our series with $97.4 \%$. Indeed, in our countries, it is the most secure, cheapest and most available orthopedic therapeutics of immobilization in emergency in the SOTH for management of CF. The average immobilization time regardless of the type of immobilization is 44.4 days. This is far from the case in the De Giorgi et al. (2011) series, which found an average of 28 days. The lack of or insufficient explanation by emergency physicians was the main reason advanced by patients who kept their immobilization tool longer than the attending physician wanted. Hill et al. (1997) found in the USA a duration of 6.1 weeks, superimposable to our result.

In our sample, the lack of poor modified Constant's score corroborates the results of Lazarides \& Zafiropoulos (2006) who found a score of 62 to 100 with an average of 84 . This score was, in our study: excellent $20.7 \%$; good $65.8 \%$; average $13.5 \%$; and varied from 60 to 94 . The Constant's "modified" score was less favorable in patients with a shortening of more than $2 \mathrm{~cm}$ compared to the contralateral clavicle $(\mathrm{p}=0.0435)$. According to McKee et al. (2006) in Canada, there is no link between the Constant score and the degree of shortening of the clavicle. This contradiction can be explained by the fact that the rating of the subjective parameters of the Constant's score (pain and activity) represents only $35 \%$ of the total score in the series of McKee et al. (2006), against nearly $60 \%$ in ours (pain, activity and driving force). SOTH does not have an objective measuring instrument of muscular strength. Robinson et al. (2004) in the UK, found in a multicenter study a mean Constant's score of 87.8 with 85.2 and 90.3 as extremes. Considering their results, pseudarthrosis and consolidation delays were rather the factors influencing the Constant's score.

More than half $(62.20 \%)$ of patients were satisfied with the results of treatment received; $37.8 \%$ were not. Our results are worse than those of De Giorgi et al. which obtained respectively $71.8 \%$ and $29.6 \%$ (De Giorgi et al., 2011); but they are still better than the results published by the Canadian Orthopedic Trauma Society (2007). It has been demonstrated by Hill et al. (1997) the link between patient dissatisfaction rate and clavicular shortening (from $02 \mathrm{~cm}$ and up). The subjective results were also related to the reported 
inconveniences ( $\mathrm{p}=0.0002)$; it was mainly a question of intense exercise pain, functional and aesthetic discomfort (especially in women).

Radiologically, the evolution of the CF in our series was marked mainly by vicious calluses in $90.4 \%$ of cases and $2.6 \%$ of nonunion. Eskola et al. (1986) reported $3 \%$ nonunion in their study. In the literature, the frequency of nonunion varies between 0.03 and 5.9\% (Maynou \& Mestdagh, 1996; Hill et al., 1997). A statistically significant correlation between the occurrence of nonunion and a clavicle shortening of more than $2 \mathrm{~cm}$ and/or an inter-fragmentary gap $(\mathrm{p}<0.01)$ was observed in our study. This link between nonunion and initial displacement has been highlighted by other authors including Hill et al. (1997) and Murray et al. (2013). Indeed, according to Murray et al. (2013), comminutive fracture line and smoking are the other factors that, in addition to the displacement of the fracture, predispose to nonunion. In a series of 941 patients in the UK, Murray et al. (2013) reported $13.3 \%$ nonunion; Hill et al. (1997) had noted 15\%. This high frequency in the Murray and Hill series can be explained by the size of their sample, a high proportion of fractures with inter-fragmentary gap and smoking. The frequency of vicious callus has been variously appreciated by the authors (Murray et al., 2013; Hill et al., 1997).

\section{Conclusion}

Clavicle fracture in adults is relatively common at Sylvanus Olympio Teaching hospital in Lomé, where the most commonly used non-operative treatment is the plaster bolero. The functional result was favorable and the radiological results were dominated by a high rate of consolidation. More than half of the patients were satisfied with the results of the nonoperative treatment. Through our favorable results, orthopedic treatment of clavicular fractures in adulthood at Teaching hospital in Lomé should be improved especially for patients who are unable to find financial resources for surgical treatment. A subsequent study comparing the orthopedic and surgical treatment of clavicular fractures in our countries will be a valuable contribution to this end.

\section{References:}

1. Canadian, O. T. S. (2007). Nonoperative treatment compared with plate fixation of displaced midshaft clavicular fractures. A multicenter, randomized clinical trial. The Journal of bone and joint surgery. American volume, 89(1), 1.

2. Available at: https://www.ncbi.nlm.nih.gov/pubmed/17200303 [consulted the 29th August 2018]

3. Cho, C. H., Song, K. S., Min, B. W., Bae, K. C., \& Lee, K. J. (2010). Operative treatment of clavicle midshaft fractures: comparison between 
reconstruction plate and reconstruction locking compression plate. Clinics in orthopedic surgery, 2(3), 154-159.

4. Available https://synapse.koreamed.org/search.php?where=aview\&id=10.4055/ci os.2010.2.3.154\&code $=0157$ CIOS $\&$ vmode $=$ FULL [consulted the 29 th August 2018]

5. Constant, C. R., \& Murley, A. H. (1987). A clinical method of functional assessment of the shoulder. Clinical orthopaedics and related research, (214), 160-164.

6. Available at: https://europepmc.org/abstract/med/3791738 [consulted the 29th August 2018]

7. De Giorgi, S., Notarnicola, A., Tafuri, S., Solarino, G., Moretti, L., \& Moretti, B. (2011). Conservative treatment of fractures of the clavicle. $B M C$ research notes, $4(1), 333$.

8. Available at: https://bmcresnotes.biomedcentral.com/articles/10.1186/1756-0500-4333 [consulted the 30th August 2018]

9. Eskola, A., Vainionpää, S., Myllynen, P., Pätiälä, H., \& Rokkanen, P. (1986). Outcome of clavicular fracture in 89 patients. Archives of orthopaedic and traumatic surgery, 105(6), 337-338.

10. Available at: https://link.springer.com/article/10.1007/BF00449938 [consulted the 28th August 2018]

11. Faldini, C., Nanni, M., Leonetti, D., Acri, F., Galante, C., Luciani, D., \& Giannini, S. (2010). Nonoperative treatment of closed displaced midshaft clavicle fractures. Journal of Orthopaedics and Traumatology, 11(4), 229-236.

12. Available at: https://link.springer.com/article/10.1007/s10195-0100113-z [consulted the 29th August 2018]

13. Hill, J. M., Mcguire, M. H., \& Crosby, L. A. (1997). Closed treatment of displaced middle-third fractures of the clavicle gives poor results. The Journal of bone and joint surgery. British volume, 79(4), 537-538.

14. Available at: https://online.boneandjoint.org.uk/doi/abs/10.1302/0301620X.79B4.0790537 [consulted the 28th August 2018]

15. Lazarides, S., \& Zafiropoulos, G. (2006). Conservative treatment of fractures at the middle third of the clavicle: the relevance of shortening and clinical outcome. Journal of shoulder and elbow surgery, 15(2), 191-194.

16. Available at: https://www.sciencedirect.com/science/article/pii/S1058274605002314 [consulted the 29th August 2018]

17. Maynou, C., \& Mestdagh, H. (1996). Fractures de la clavicule. Cahiers d'enseignement de la SOFCOT, 56, 143-152. 
18. Available https://scholar.google.com/scholar?hl=en\&as_sdt=0\%2C5\&q=Maynou $+\mathrm{C} \% 2 \mathrm{C}+$ Mestdagh $+\mathrm{H} .+$ Fractures+de+la+clavicule. $+\& b \operatorname{tnG}=$ [consulted the 29th August 2018]

19. McKee, M. D., Pedersen, E. M., Jones, C., Stephen, D. J., Kreder, H. J., Schemitsch, E. H., ... \& Potter, J. (2006). Deficits following nonoperative treatment of displaced midshaft clavicular fractures. JBJS, $88(1), 35-40$.

20. Available

at: https://journals.lww.com/jbjsjournal/subjects/Shoulder/Fulltext/2006/0 1000/DEFICITS_FOLLOWING_NONOPERATIVE_TREATMENT_ OF.5.aspx [consulted the 29th August 2018]

21. Murray, I. R., Foster, C. J., Eros, A., \& Robinson, C. M. (2013). Risk factors for nonunion after nonoperative treatment of displaced midshaft fractures of the clavicle. JBJS, 95(13), 1153-1158.

22. Available

at:

https://journals.lww.com/jbjsjournal/subjects/Pediatrics/Abstract/2013/

07030/Risk_Factors_for_Nonunion_After_Nonoperative.1.aspx [consulted the 30th August 2018]

23. Postacchini, F., Gumina, S., De Santis, P., \& Albo, F. (2002). Epidemiology of clavicle fractures. Journal of Shoulder and Elbow Surgery, 11(5), 452-456.

24. Available

at: https://www.sciencedirect.com/science/article/pii/S1058274602000678 [consulted the 27th August 2018]

25. Robinson, C. M. (1998). Fractures of the clavicle in the adult: epidemiology and classification. The Journal of bone and joint surgery. British volume, 80(3), 476-484.

26. Available at: https://online.boneandjoint.org.uk/doi/abs/10.1302/0301620x.80b3.0800476 [consulted the 29th August 2018]

27. Robinson, C. M., McQueen, M. M., \& Wakefield, A. E. (2004). Estimating the risk of nonunion following nonoperative treatment of a clavicular fracture. JBJS, 86(7), 1359-1365.

28. Available

at: https://journals.lww.com/jbjsjournal/subjects/Shoulder/Fulltext/2004/0 7000/Estimating_the_Risk_of_Nonunion_Following.2.aspx [consulted the 29th August 2018] 